\title{
Air-Water Cooling System for Switch-Mode Power Supplies
}

\author{
G. Casano, S. Piva \\ ENDIF-Engineering Department in Ferrara, Università di Ferrara, Ferrara, Italy \\ Email: giovanni.casano@unife.it, stefano.piva@unife.it
}

Received 19 June 2015; accepted 13 September 2015; published 16 September 2015

Copyright (C) 2015 by authors and Scientific Research Publishing Inc.

This work is licensed under the Creative Commons Attribution International License (CC BY). http://creativecommons.org/licenses/by/4.0/

(c) (i) Open Access

\section{Abstract}

The results are presented of an experimental investigation of heat transfer in an air-liquid cooling system for a Switch-Mode Power Supply (SMPS) for TV digital power amplifiers. Since these SMPSs are characterized by high power and high compactness, thereby making the standard cooling techniques difficult to be used, a new cooling system is developed, using water and air as the cooling media. The active components (MOSFETs) are cooled with a liquid cold-plate, the passive ones (condensers, transformers, coils) with an air flow, in turn cooled by the cold-plate. By inserting the cooling system in an experimental tool where it is possible to control the cooling water, measurements are made of temperature in the significant points of the SMPS. The electric efficiency is also measured. The evaluation of the thermal performance of this cooling system is useful in order to limit its maximum operational temperature. The efficacy of the cooling system is demonstrated; the trends of efficiency and power dissipation are evidenced.

\section{Keywords}

Switch Mode Power Supply SMPS, Cold-Plate, Cooling System, Thermal Design

\section{Introduction}

In recent times, switching regulators are used as replacements for traditional (linear) regulators when high efficiency, small size and low weight are required [1]. A Switch-Mode Power Supply (SMPS) is an electronic power supply unit that incorporates a switching regulator to convert electrical power efficiently. Like other power supplies, a SMPS transfers power from a source to a load, while converting voltage and current characteristics. Unlike more conventional power supplies, a SMPS minimizes the wasted energy and ideally dissipates no power. This higher efficiency in power conversion is an important advantage of a SMPS, commonly coupled to smaller size and lower weight than a linear supply, due to smaller size and lower weight of the transformer. 
Main characteristics of SMPSs are then high electric efficiency and reduced cooling requirements [2] [3]. However, as usual in power electronics, the power of these SMPSs is increased in time; the heat release is thence once again large and thus efficient cooling systems are needed. Liquid cooling can then become an interesting solution, also because it allows a significant size reduction of the equipment in line with the requirements of electronics design [4].

In these equipments the liquid cooling is obtained with cold-plates, consisting of a plate, usually in aluminium, on which are fixed some electronic components and within which one or more hydraulic circuits are obtained for their cooling with water flowing in forced circulation [5].

While it is easy to collocate the active components on a cold plate, the large number of passive components of a SMPS, like condensers, transformers and coils, needs to be placed on a printed circuit board (PCB). It is difficult with a cold plate to maintain the PCB and these passive components at the design temperature, because they are originally developed for air cooling.

In this paper the results are presented for an experimental investigation of heat and fluid flow in a liquid cooled SMPS for TV digital power amplifiers. The objective is to quantify the performance of a new cooling system being designed to dissipate the heat generated by the active and passive electronic components of this SMPS, in order to limit their maximum temperature during operations. The active components are cooled with the liquid cold-plate. For the PCB, hosting the passive components, we create a sealed enclosure over the cold plate, where a forced airflow is driven by small fans (Figure 1). The air flow is used to cool the passive components; this air flow is cooled with a finned heat sink, in turn cooled by the cold plate.

Measurements are made of temperature in the significant points of the SMPS. Both the power consumed from the electricity network and that being supplied to an electrical dummy load are measured, in order to verify the electric efficiency of the SMPS and its dependence on the thermal and electric parameters. The cooling system is placed in an experimental tool where it is possible to measure and control the flow of the cooling liquid. A detailed analysis of the thermal behaviour of this cooling system is given. Finally, the practical significance of the problem is discussed.

\section{Experiment}

The experiment consists of a hydraulic testing circuit where we can insert a test section, in this case the cold plate holding the SMPS to be tested. In Figure 2, it is reported a sketch of the hydraulic loop with a cold-plate as the test section.

The tested SMPS supplies a variable voltage from $+25 \mathrm{~V}$ to $+50 \mathrm{~V}$. It uses a mix of surface mount and traditional technology to reduce the space occupied as far as possible. The SMPS disposes of thermal $\left(70^{\circ} \mathrm{C}\right.$ on the transformer) and current (100 A) protections. It was originally designed for air cooling; we modified the SMPS to install it in the cooling system discussed in Par. 1. The modifications were particularly simple, because the active components (MOSFETs) were originally placed on the finned vertical sides of the SMPS. We dismounted the fins and placed the MOSFETs in direct connection with the cold-plate (Figure 3 and Figure 4).

To simulate real operating conditions, a dummy load was connected to the power supply output. To identify

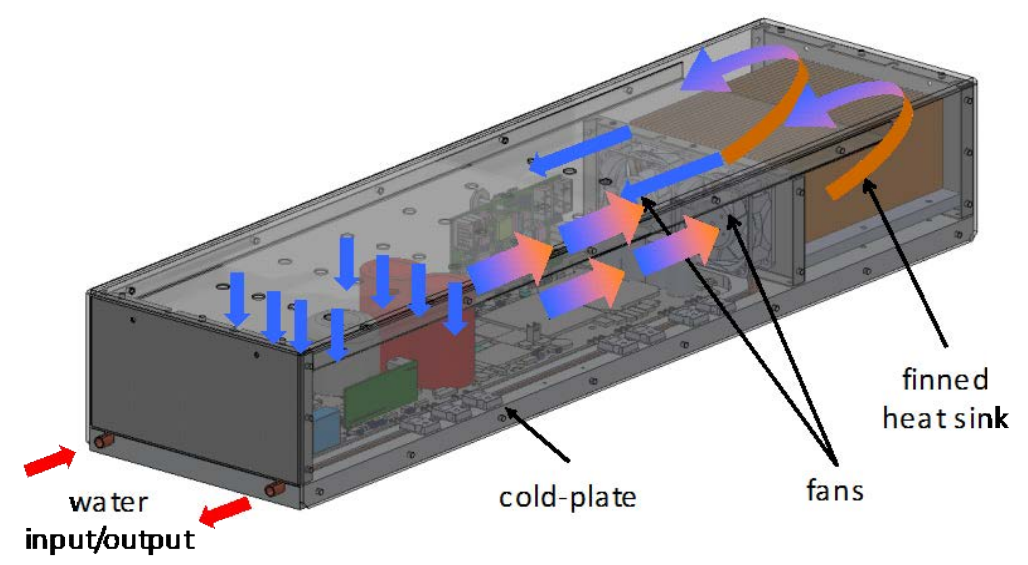

Figure 1. View of the closed air cooling system. 

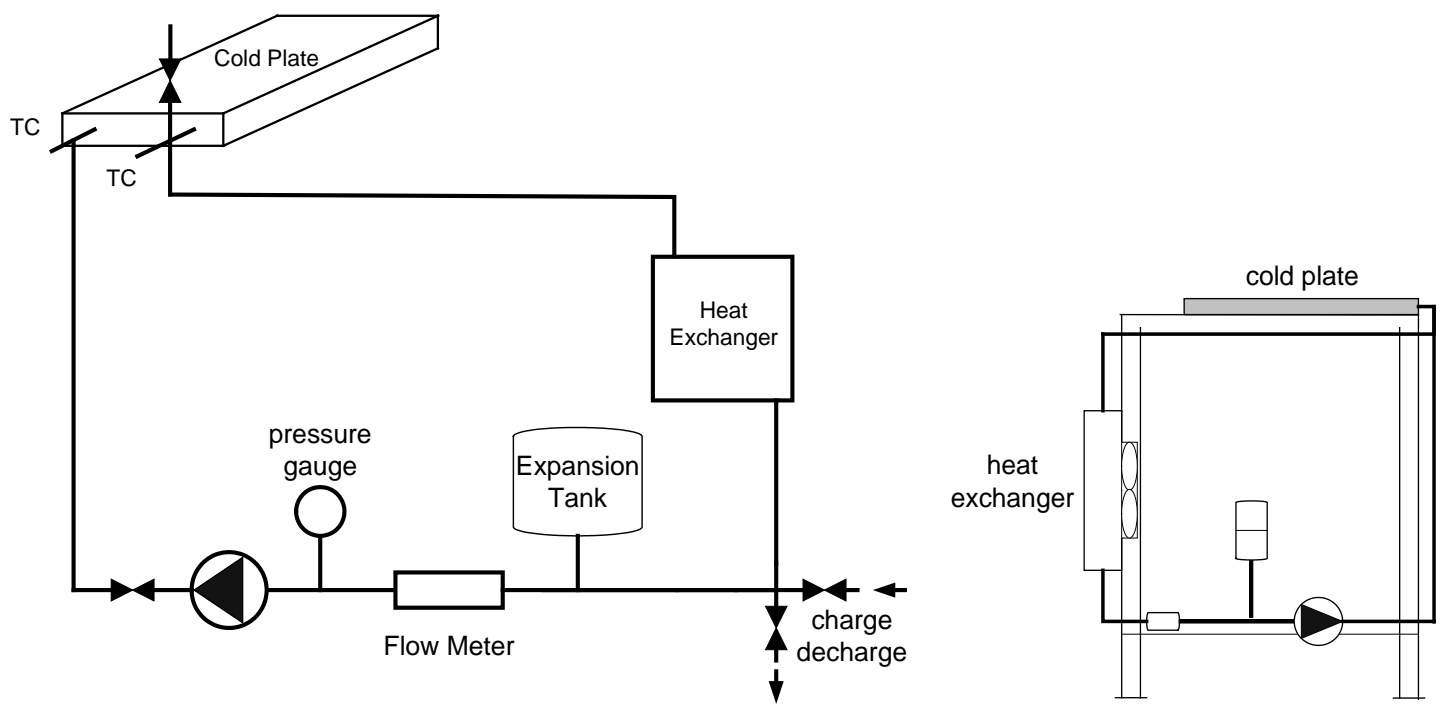

Figure 2. Sketch of the hydraulic loop with a cold plate as the test section.
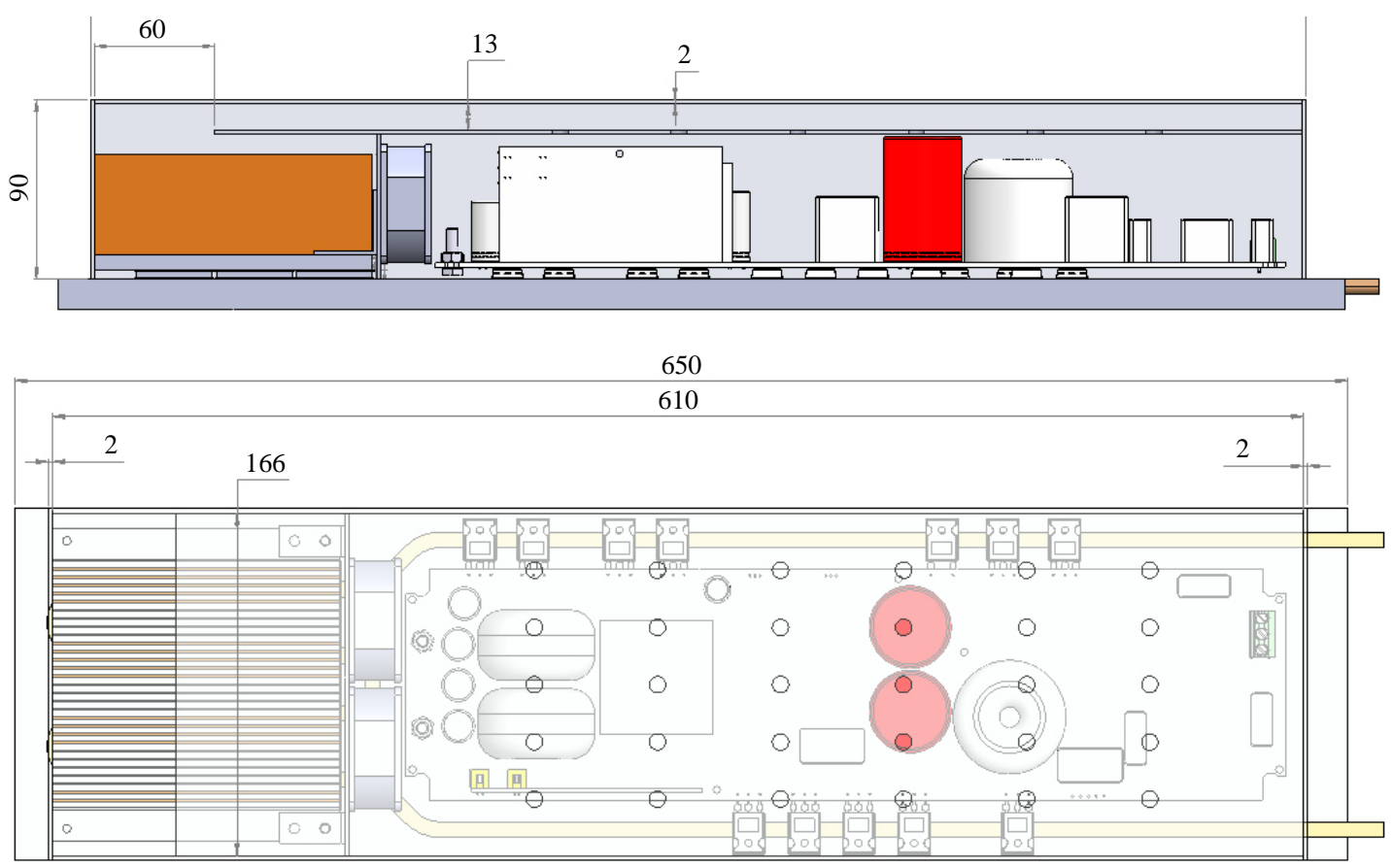

Figure 3. Lateral and top view of the cold plate with the PCB and the cooling system.

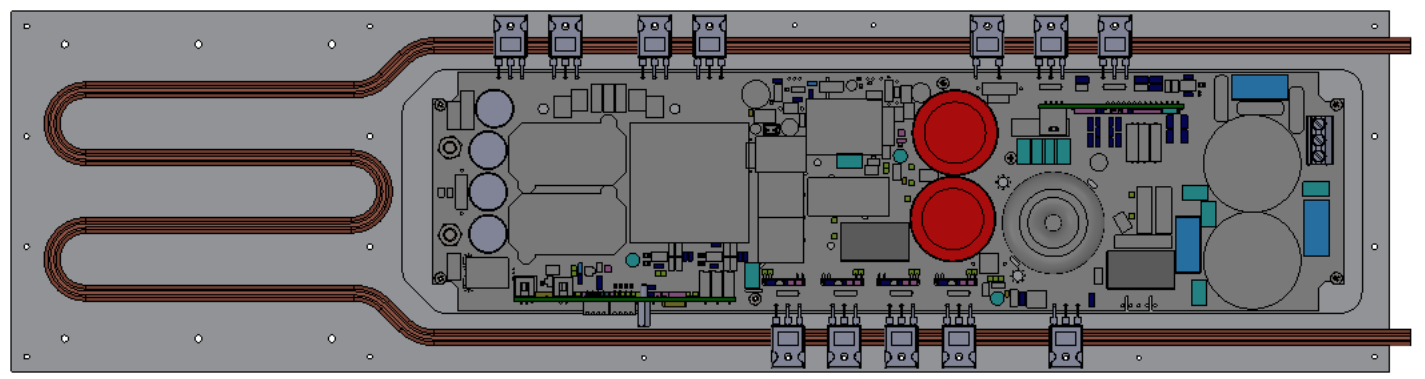

Figure 4. Top view of the cold plate with the PCB of the SMPS. 
the components thermally stressed, twenty-five thermocouples were placed in the most significant points of the apparatus. To qualify the performance, both the power exchanged with the cooling water and the efficiency, given by the ratio of the power dissipated in the dummy load to that taken from the grid, was measured.

\subsection{Test Section}

The test section consists of a cold-plate with the PCB of the SMPS, where the active and passive electronic components are positioned. A view of the cold plate with the PCB is shown in Figure 3.

In a SMPS both the active components and the passive ones generate significantly heat, which must be dissipated to control their temperature. In this SMPS the main active components are 12 MOSFETs. They come out from the long sides of the PCB, 5 on one side and 7 on the other one, so as to be cooled directly on the "cold plate". Among the passive components, the most significant are: a transformer, three coils and two large electrolytic capacitors. These components, placed on the PCB and characterized by a significant three-dimensional space occupation, cannot be directly cooled on the cold plate. For this reason they are cooled by forced convection by means of a suitable air flow, generated by a pair of fans.

The "press-fit" cold plate consists in an aluminium plate (thickness $10 \mathrm{~mm}$ ) where a cooling circuits is manufactured with a copper pipe (external diameter $6 \mathrm{~mm}$ ) pressed in a channel machined on the surface of the plate. The pipe runs longitudinally along the sides of the plate. The active components (MOSFETs) are placed on the copper pipe to facilitate their cooling. The cold plate is used as the base of a closed enclosure where a flow of air is maintained. Sides and cover of the enclosure are in transparent polycarbonate. This forced flow is used to cool the passive components.

A view of the cold plate is shown in Figure 4. Inlet and outlet of the pipe are on the same side. On the opposite side, the pipe is bended to form a coil. Over the coil is placed a finned heat sink. A thin thermal interface Bergquist Sil Pad $900 \mathrm{~S}$ (thickness $0.229 \mathrm{~mm}$, thermal conductivity $1.6 \mathrm{~W} \cdot \mathrm{m}^{-1} \cdot \mathrm{K}^{-1}$ ) is placed between the heat sink and the cold plate. In front of the finned heat sink (Figure 5) we placed two fans Ebm Papst $500 \mathrm{~F}$ (external sides $50 \times 50 \mathrm{~mm}$ ). These fans collect warm air from the passive components of the PCB and push it into the finned cooling surface. The finned heat sink is made of aluminium (base $151 \times 157 \mathrm{~mm}$ ); the fins (31) are 30 $\mathrm{mm}$ high, $135 \mathrm{~mm}$ long, $1 \mathrm{~mm}$ thick and are separated by a $3 \mathrm{~mm}$ throat.

The test section was instrumented to measure the temperature. The passive components (capacitors, inductances and electric transformers) were instrumented with "T type" thermocouples. The surface temperature of the pipe was measured with four thermocouples (input and output, upstream and downstream of the coil). Six thermocouples were placed in different positions on the base of the throats of the finned heat sink. Two armoured " $T$ type" thermocouples were placed upstream and downstream of the finned heat sink to measure the temperature of the internal air flow.

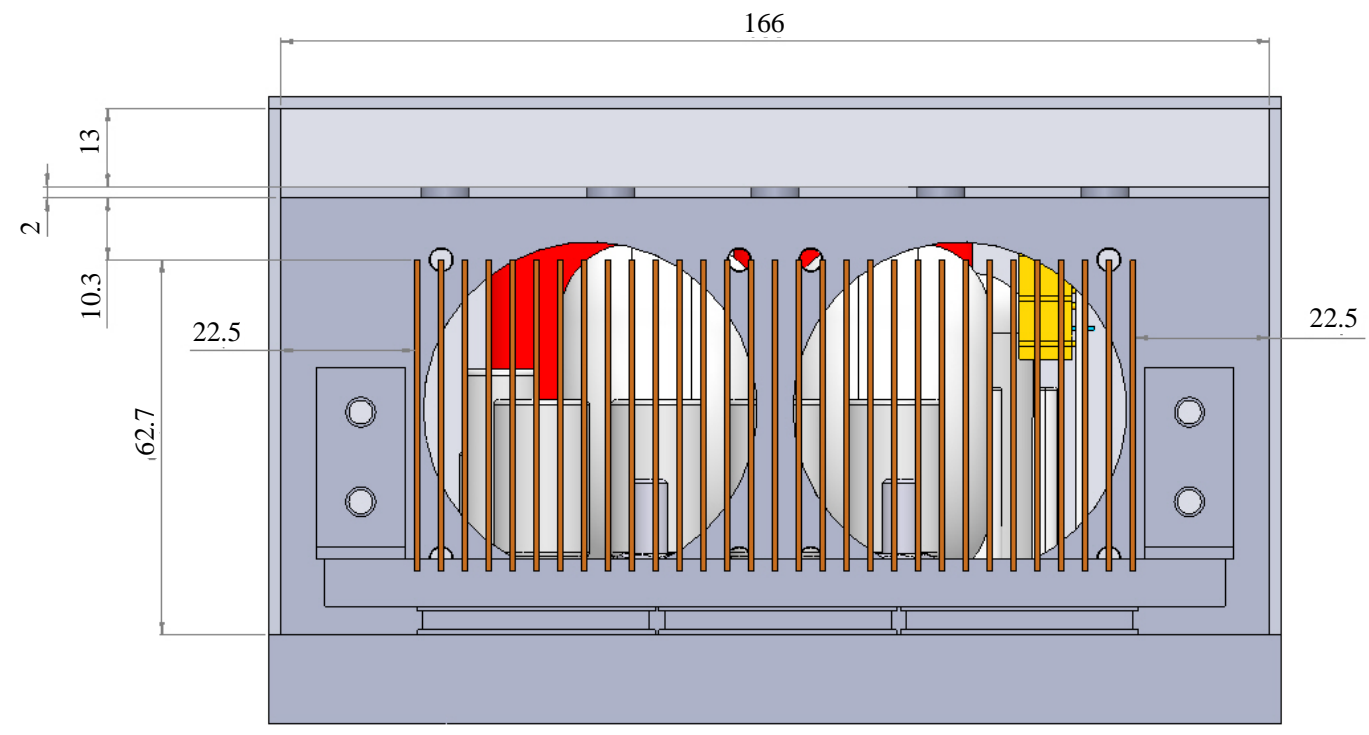

Figure 5. View of the finned heat sink with the fans. 
During the tests the SMPS was connected to a $5 \mathrm{~kW}$ dummy load. Both the electric power absorbed by the grid and that dissipated in the dummy load were measured.

The data acquisition of temperature and electrical parameters was carried out with a multimeter Agilent HP34970A. This multimeter was connected to a notebook by means of a GPIB-USB interface. The data acquisition was carried out by means of a software developed in Labview (release 8.2) environment.

\subsection{Hydraulic Loop}

A schematic diagram of the hydraulic loop is shown in Figure 2. The water flow was maintained by a pump Laing S4-36/550 P. The water flow was cooled in an aluminium air-water heat exchanger Aavid Thermalloy. The flow rate was measured in an ultrasonic flow rate meter Danfoss Sonometer 1100.

The temperature of the air flow incoming and leaving the heat exchanger was measured with armoured " $T$ type" thermocouples. The temperature of the water was measured by armoured " $T$ type" thermocouples at the cold plate inlet and outlet. The flow-meter was connected to the notebook by means of a RS232-USB adapter.

\subsection{Data Reduction and Measuring Uncertainties}

In the discussion of the results (Par. 3) are shown measured values of temperature, heat released to the water, power absorbed from the grid and efficiency. The different runs are denoted by the power absorbed by the SMPS, its output voltage and the fan voltage. No particular procedures for data reduction was used. The water cooling flow rate was the same for the whole set of experiments.

The overall accuracy of temperature measurements was estimated to be better than $0.2^{\circ} \mathrm{C}$. The relative overall uncertainty of the power exchanged with the water reaches $15 \%$ at maximum, whereas for the power absorbed from the grid and for efficiency is lower than $3 \%$ and $4 \%$, respectively. The high uncertainty of the heat released to the water, calculated through an energy balance based on water flow rate and temperature difference, is mainly due to the uncertainty of the temperature difference $(\approx 14 \%)$ and less to the flow rate $(\approx 3 \%)$.

\section{Results and Discussion}

Due to the presence of the air-cooling system, it was impossible for us an analysis of the temperature distribution on the PCB with infrared thermography, as suggested in [6]. For the identification of the most critical elements between the passive components placed on the PCB, we measured their temperature with thermocouples. For a typical experiment the temperature distribution is shown in Table 1. At high power $(P \geq 2.5 \mathrm{~kW})$ the most critical point was for thermocouple 107, placed on the transformer. At lower power $(P<2.5 \mathrm{~kW})$ the most stressed component was a winding (thermocouple 111). However, even if we are aware of this change, we used the values of the thermocouple 107 (transformer) as the reference for the discussion, because in this point the maximum temperature is attained.

Before discussing the thermal performance of the SMPS, it is opportune to discuss the distribution of temperature in the air inlet of the finned heat sink, because this parameter is particularly significant to characterize the

Table 1. Temperature on the different passive components.

\begin{tabular}{ccccccccc}
\hline & \multicolumn{7}{c}{ Power to the dummy load $(\mathrm{kW})$} \\
\cline { 2 - 8 } Temperature $\left({ }^{\circ} \mathrm{C}\right)$ & 0.5 & 1 & 1.5 & 2 & 2.5 & 3 & 3.5 \\
\hline transformer 101 & 35.9 & 37.6 & 40.1 & 44.2 & 48.9 & 54.8 & 61.4 \\
transformer 104 & 34.8 & 36.4 & 38.3 & 41.3 & 45.0 & 49.4 & 55.0 \\
transformer 107 & 33.8 & 36.6 & 39.8 & 36.1 & 50.9 & 58.5 & 66.7 \\
winding 103 & 37.6 & 39.6 & 41.3 & 44.0 & 47.6 & 52.0 & 57.0 \\
winding 111 & 38.4 & 41.2 & 43.2 & 46.4 & 50.5 & 55.7 & 61.6 \\
coil 108 & 33.9 & 39.6 & 37.9 & 41.2 & 45.1 & 50.2 & 66.7 \\
coil 109 & 31.6 & 35.6 & 34.7 & 37.0 & 40.0 & 42.9 & 56.0 \\
\hline
\end{tabular}


performance of the air cooling system. Due to the high number of thermocouples and the limited space available inside the SMPS, we were able to measure the internal air temperature at the inlet of the finned heat sink just with a single thermocouple. In Figure 6, it is shown the cross distribution of this temperature, which is measured in a plane placed $26.5 \mathrm{~mm}$ before the entrance of the finned heat sink. For reasons of symmetry, only half channel is shown. The vertical lines show the position of the openings of the fan. As evident in Figure 6, the temperature distribution in front of the fan is quite uniform along a cross section and this justifies the opportunity to characterize the air temperature with a single measurement.

First of all, we need to discuss the efficiency of the cooling system. Figure 7 shows four distributions of temperature: ambient air, internal air after the finned heat sink, water at the inlet of the cold plate, surface of the transformer exposed to air flow. The whole set of data refers to a same DC power (3006.2 $\pm 0.4 \mathrm{~W}$ ) dissipated in the dummy load for the same voltage $(40.8 \mathrm{~V})$. The temperature distributions are shown as a function of the fan voltage. This is proportional to the speed of rotation of the fan and consequently, through the fan similarity, to the air flow rate in the equipment. A higher fan voltage means a higher flow rate. The whole set of data was collected during the same day; it was difficult to obtain a constant ambient temperature in the room where the

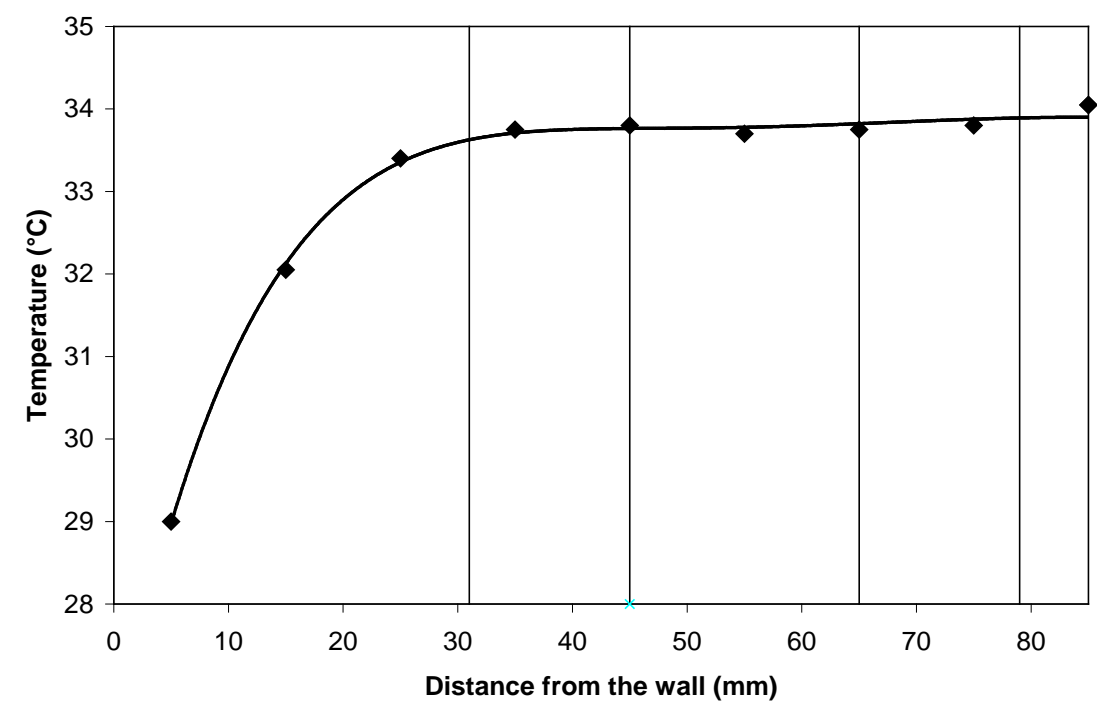

Figure 6. Temperature in a half cross section of the SMPS.

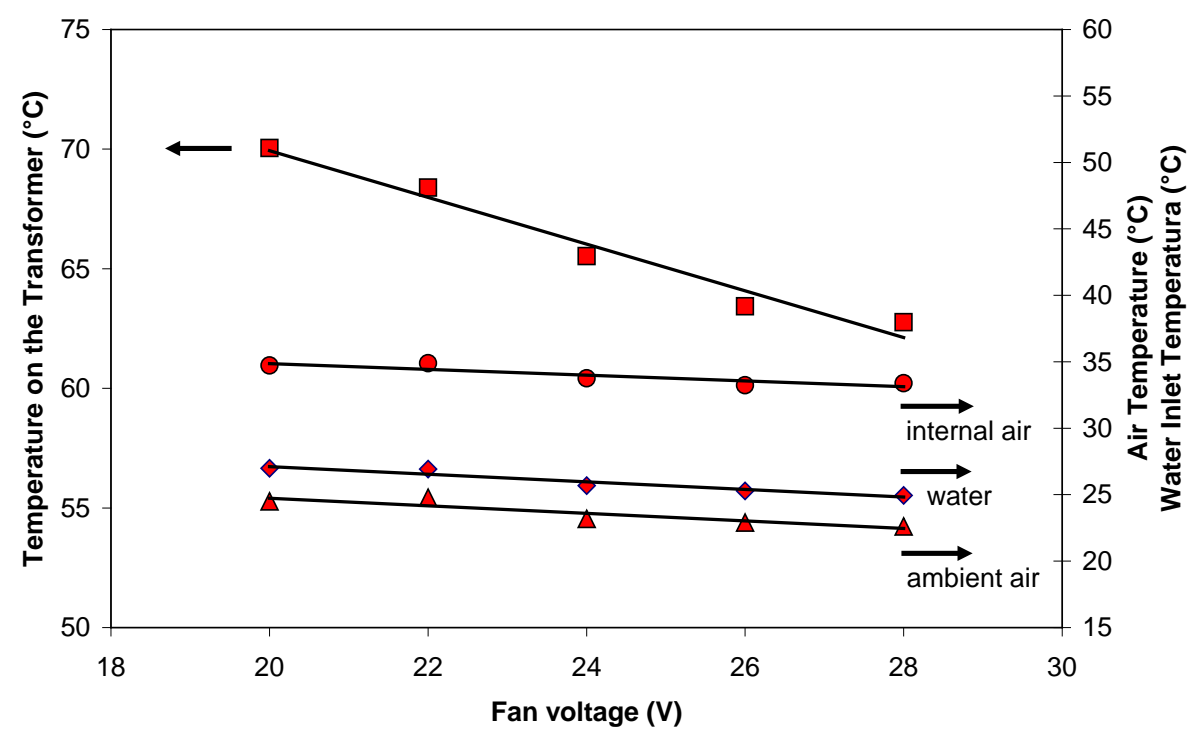

Figure 7. Temperature for the different cooling media of the SMPS. 
dummy load was dissipating $3 \mathrm{~kW}$. We started with $28 \mathrm{~V}$ (high flow rate) and then lowered the fan tension up to $20 \mathrm{~V}$ (low flow rate). A drift of the ambient temperature is evident. The inlet temperature of the cooling water in the cold-plate follows strictly the ambient temperature. The temperature on the surface of the transformer diminishes when increasing fan rotation. However, the dependency of the temperature on the surface of the transformer on the fan speed is stronger than that of the ambient temperature. It is evident in Figure 7 that an increased flow rate means a lower transformer temperature and thus the efficiency of the cooling system is demonstrated.

In Figure 8 a daily set of measurements is shown. The groups of data refer to different values of power dissipated in the dummy load. The time interval between the different groups is due to the time needed for the attainment of the steady state. This interval increases with the power. While air temperature data show an appreciable dispersion of values, the temperature on the surface of the transformer shows a smaller dispersion, helped in this by the thermal inertia of the system.

In Figures 9-13 the values are shown of different daily data sets gathered in different days. Each data set is characterized by a constant value of the voltage on the dummy load. The data are shown as a function of the power absorbed by the grid.

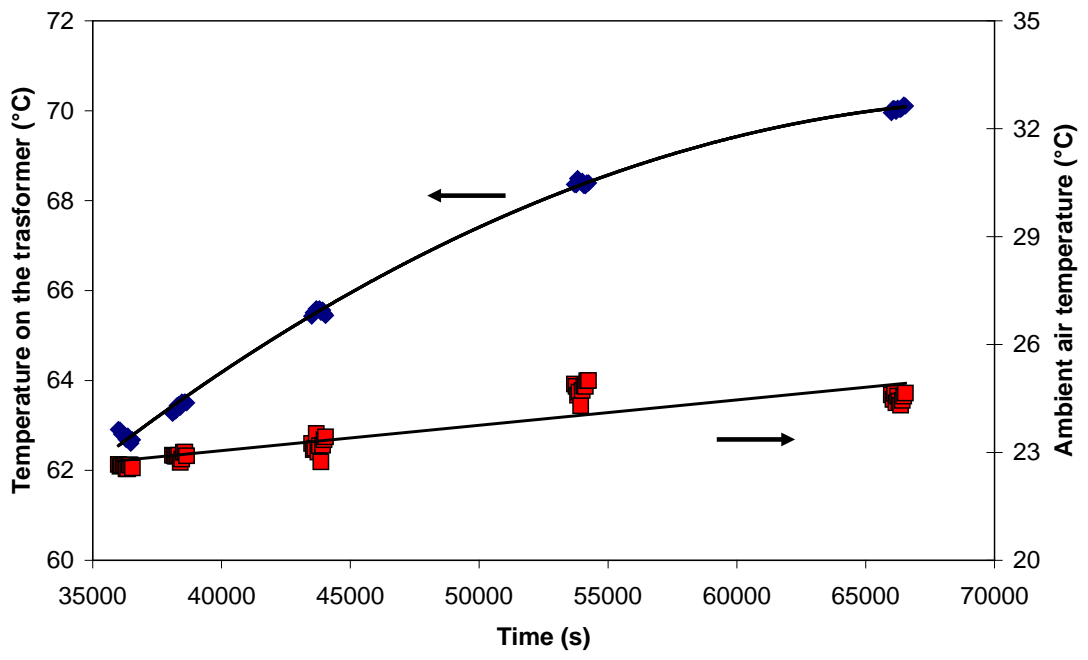

Figure 8. Daily temperature distributions for a data set.

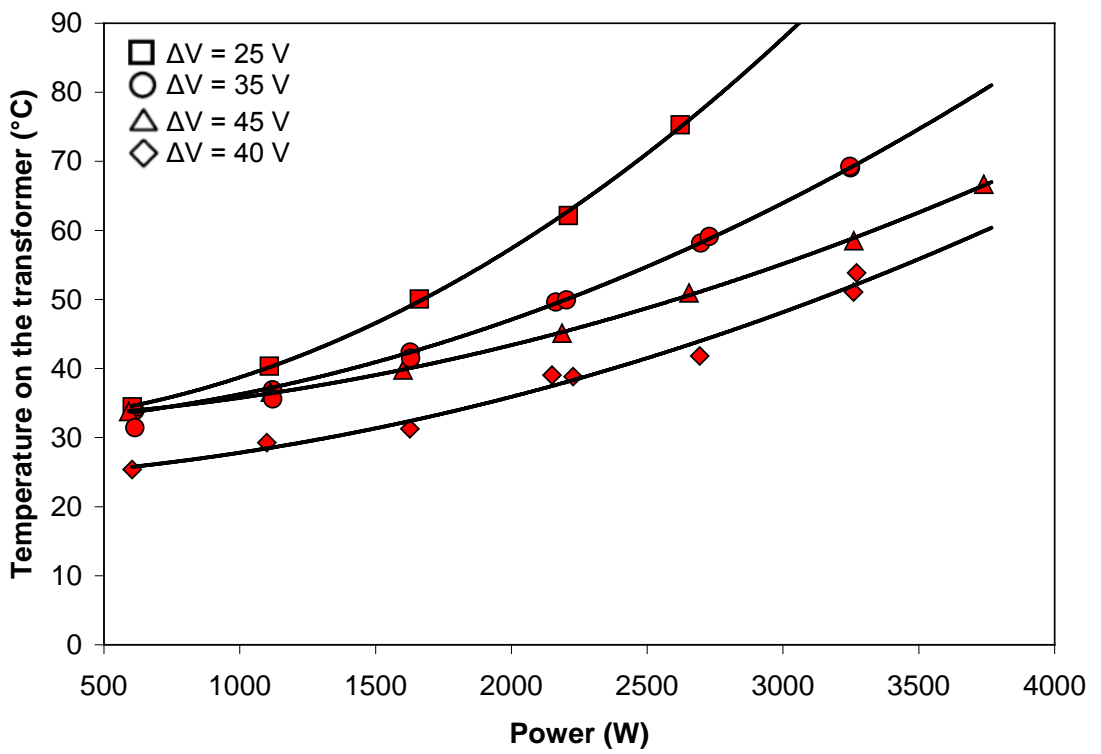

Figure 9. Temperature on the transformer for different powers. 


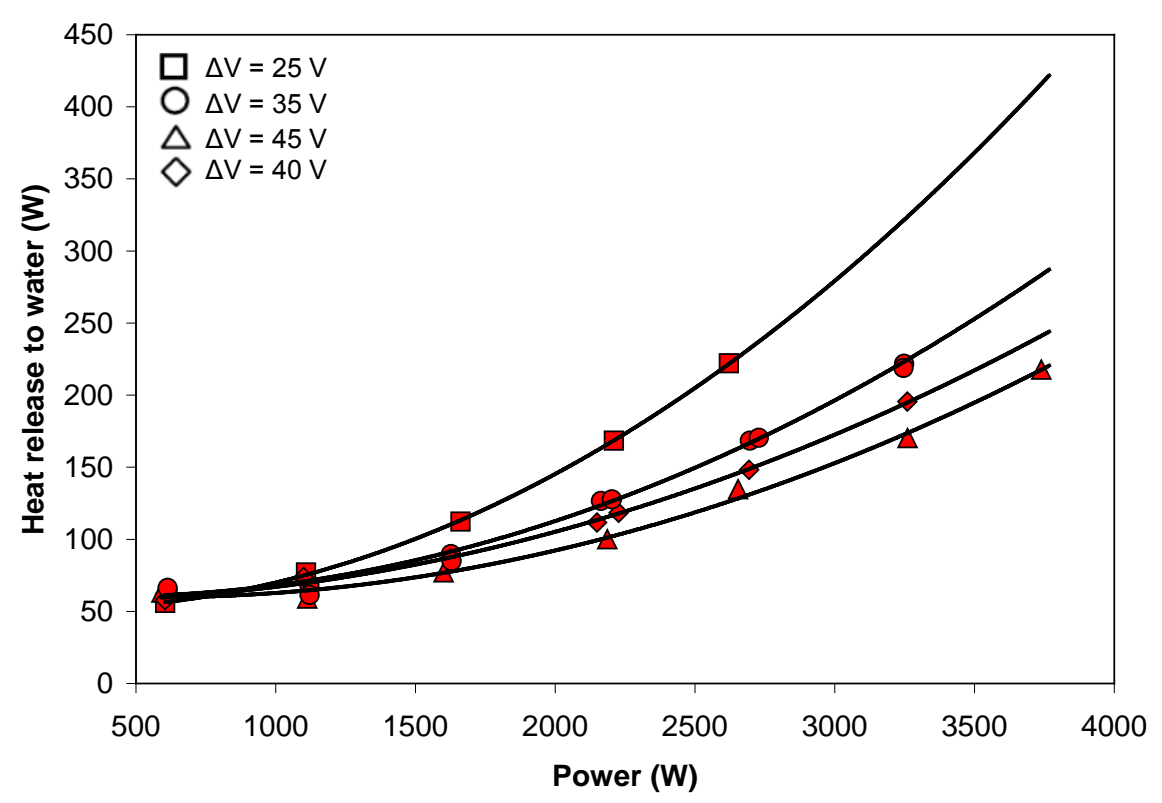

Figure 10. Heat released to water for different powers.

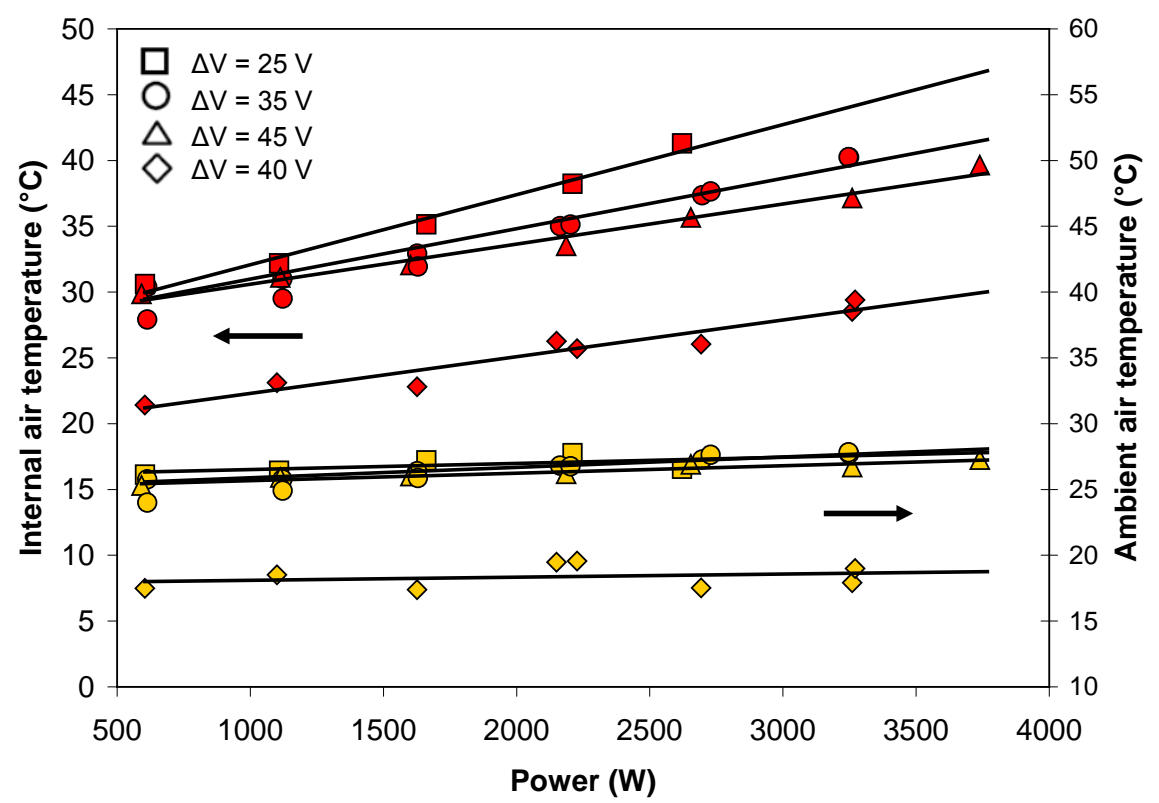

Figure 11. Ambient and internal air temperature for different power (dark symbols: internal air; pale symbols: ambient air).

In Figure 9 the distributions are shown of the highest temperature on the passive components (in this SMPS this is the temperature on the surface of the transformer) for four data sets characterized by a different voltage of the power dissipated on the dummy load. The tests for $\Delta \mathrm{V}=25,35$ and $45 \mathrm{~V}$ were held in May, with a higher air ambient temperature, while that for $\Delta \mathrm{V}=40 \mathrm{~V}$ was held during winter (February), with a lower ambient air temperature. These distributions can be well interpolated by second order polynomials. Higher values of temperature on the transformer are reached for lower voltages on the dummy load. The three "spring" data sets show temperature distributions in good accordance, starting from the same value and increasing with an exponent proportional to the voltage. The "winter" distribution shows a growth in good accordance with those characterizing the "spring" data sets, but with a lower starting point for temperature.

In Figure 10 the distributions are shown of the heat released to the cooling water, for the same data sets of 


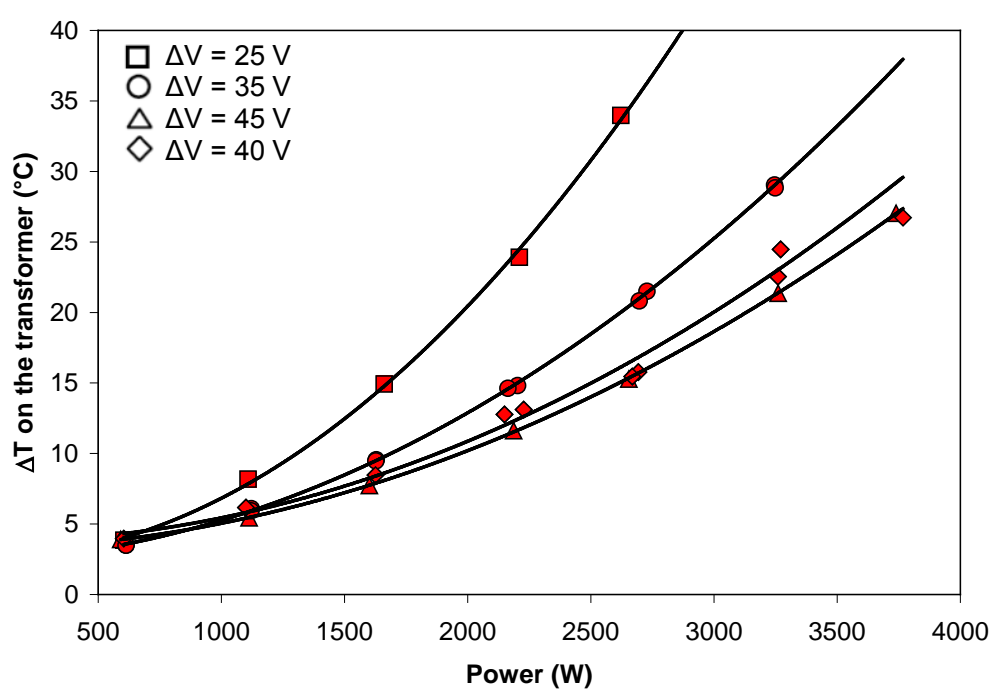

Figure 12. Temperature difference between transformer and internal air.

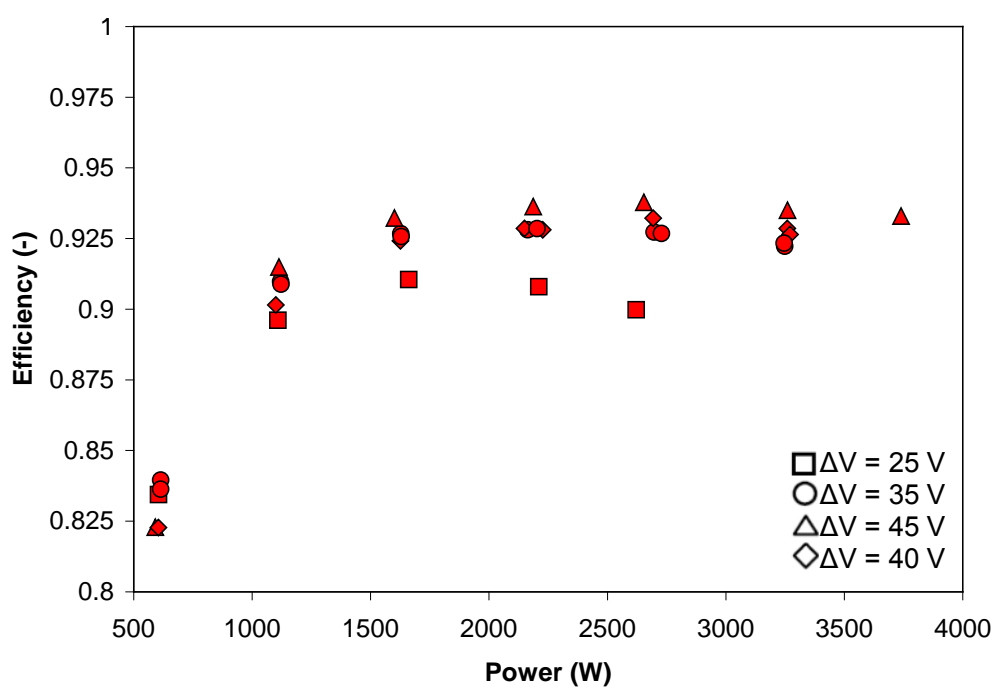

Figure 13. Efficiency as a function of the power for different output voltages.

Figure 9. These distributions can be well interpolated by second order polynomials. As for the temperature on the transformer, higher values of thermal power exchanged with the cold plate are reached for lower voltages on the dummy load. The main difference between Figure 9 and Figure 10 is that the power exchanged with the water is not influenced by the season.

In Figure 11, the internal and external air temperature distributions are shown. The ambient air in the "spring" data sets is practically constant during the day and the same for the different voltages; this temperature is $10^{\circ} \mathrm{C}$ higher than that of the "winter" data set. The internal air temperature is always higher. The gap between "spring" and "winter" ambient air data is maintained for the internal air temperature. The latter parameter shows a marked tendency to increase with the electric power. This tendency is affected also by the operating conditions of the SMPS. The latter is designed for a voltage on the load of $45 \mathrm{~V}$; lower voltages mean higher dissipations and higher temperature.

As observed in Figure 9, a strong dependency of the temperature on the surface of the transformer on the ambient air temperature, is evident. In Figure 11 we observed a strong dependency of the internal air temperature on the ambient air temperature. Since the heat release trends are independent of the ambient air temperature (Figure 10), and since the air flow rate is the same, the temperature difference between transformer and air must 
be the same. This result is confirmed in Figure 12, where is shown the temperature difference between envelope of the transformer and internal cooling air. The previous dependency on the ambient air is lost and the whole set of data follows the same rule of dependency on the electric power and on the voltage of the power dissipated in the dummy load. Furthermore, the distributions of temperature difference are characterized by the behaviour of second-order polynomial, due to the combination of a parabola (Figure 9) with a straight line (Figure 11).

In Figure 13 the efficiency of the SMPS, determined as the ratio of the power dissipated in the dummy load to that absorbed from the electric grid, at part load and for different output voltages is shown. The efficiency is higher at the design voltage $(\Delta \mathrm{V}=45 \mathrm{~V})$ and reduces for decreasing output voltages. For the design output voltage $(\Delta V=45 \mathrm{~V})$ the efficiency curve is flat in the load range $30 \% \div 100 \%$.; for lower values of power, the efficiency drops rapidly with the load. The efficiency curve changes for lower values of output voltage. The load range characterized by a flat efficiency narrows and moves towards low values of power for decreasing values of the output voltage. For example, at the output voltage $\Delta \mathrm{V}=25 \mathrm{~V}$, the maximum efficiency shows a narrow interval around $1500 \mathrm{~W}$ and significant decreases of efficiency for higher and lower values of power.

\section{Concluding Remarks}

An experimental investigation has been carried out of the thermal behaviour for a liquid-cooled SMPS to be used in TV digital power amplifiers. In the cooling system a cold plate and a forced air flow are coupled to cool the active and passive electronic components, respectively. The cooling system has been tested for different working conditions which are consistent with the manufacturer's operational conditions. Useful information has been obtained on the temperature distribution in the thermally stressed components of the device. The experimental investigation is allowed to establish the limiting working conditions of the cooling system.

The heat released to the cooling water, as a function of the working conditions, is an important data, as much as the temperature of the internal air flow. In particular, we focused on the transformer, the most critical component on the thermal point of view. Significant data have been gathered for the temperature difference between internal air and casing of the transformer.

A strong dependency of the thermal power dissipated by the SMPS on the electric operating conditions is clearly evidenced.

Based on these data it is possible to suggest some lines of development of the cooling system. The internal air circulation can be modified to obtain a more efficient flow on the critical components. This can be obtained with different fans and/or with a different distribution of the holes over the passive components. Furthermore, due to the limited available spaces, the system "fans and fins" is not particularly efficient. This system can be redesigned for a better distribution of air between the fins.

\section{Acknowledgements}

The financial support of ELENOS Srl is gratefully acknowledged.

\section{References}

[1] Mohan, N., Undeland, T.M. and Robbins, W.P. (2003) Power Electronics: Converters, Applications, and Design. 3rd Edition, Wiley, New York.

[2] Koizumi, K., Joboji, A., Nagahara, K. and Ishizuka, M. (2003) Thermal Analysis of Natural Convection Cooled Switch Mode Power Supplies. 2003 International Electronic Packaging Technical Conference and Exhibition, Maui, 6-11 July 2003, 103-109. http://dx.doi.org/10.1115/ipack2003-35048

[3] Koizumi, K., Joboji, A., Nagahara, K. and Ishizuka, M. (2004) Development of Thermal Flow Simulation Method for Switch Mode Power Supplies and Its Integration with Electric Circuit Analysis (in the Case of Natural Convection Air Cooled Switch Mode Power Supply). Heat Transfer-Asian Research, 33, 473-489. http://dx.doi.org/10.1002/htj.20037

[4] Hiraki, M., Kano, T., Kizu, H., Satoh, H., Yamashita, S., Kobayashi, K., Tanaka, H., Arai, Y., Satoh, K. and Fuchigami, K. (1989) Water-Cooled Switching Power Supply. 11th International Telecommunications Energy Conference, 2, 20.8/1-20.8/7.

[5] Sabin, M. and Piva, S. (2014) Numerical Analysis of a Cold Plate for FM Radio Power Amplifiers. Journal of Physics: Conference Series, 525, Article ID: 012001. http://dx.doi.org/10.1088/1742-6596/525/1/012003

[6] Valdova Antonova, A., Tural, E. and Stanchev Andreev, A. (2008) Contactless Thermal Characterization Method of Switching Mode Power Supply. Vol. 4, Proc. of Electronics' 2008, Sozopol, 24-26 September 2008, 3-8. 